\title{
Control of stomatal aperture and carbon uptake by deficit irrigation in two grapevine cultivars
}

\author{
Claudia R. de Souza ${ }^{\mathrm{a}, \mathrm{c}}$, João P. Maroco ${ }^{\mathrm{a}, \mathrm{b}}$, Tiago P. dos Santos ${ }^{\mathrm{c}}$, \\ M. Lucília Rodrigues ${ }^{\mathrm{c}}$, Carlos Lopes ${ }^{\mathrm{c}}$, João S. Pereira ${ }^{\mathrm{c}}$, M. Manuela Chaves ${ }^{\mathrm{a}, \mathrm{c}, *}$ \\ ${ }^{a}$ Laboratório de Ecofisiologia Molecular, Instituto de Tecnologia Química e Biológica, Apartado 127, 2780-901 Oeiras, Portugal \\ ${ }^{\mathrm{b}}$ Instituto Superior de Psicologia Aplicada, Rua Jardim do Tabaco 34, 1149-047 Lisboa, Portugal \\ ${ }^{\mathrm{c} I n s t i t u t o}$ Superior de Agronomia, Tapada da Ajuda, 1349-017 Lisboa, Portugal
}

\begin{abstract}
Improvements in water use efficiency of crops are essential under the scenarios of water scarcity predicted by global change models for the Mediterranean region. In recent years, deficit irrigation, including partial root drying (PRD), has been proposed as an irrigation technique to improve water use efficiency and standardize grapevine yield and quality. The objective of this study was to evaluate the impact of deficit irrigation on photosynthetic responses of field grown grapevines of $\mathrm{cv}$. Moscatel and Castelão. The treatments were: full irrigation (FI), corresponding to $100 \% \mathrm{ET}_{\mathrm{c}}$; non-irrigated, but rain fed (NI) and partial root zone drying (PRD) and deficit irrigation (DI), both corresponding to an irrigation of 50\% $\mathrm{ET}_{\mathrm{c}}$. While in the DI treatment water was applied to both sides of the root system, in the PRD treatment, water was supplied to only one side of the root system, alternating sides periodically. In both cultivars, PRD and DI vines showed intermediate pre-dawn leaf water potential $\left(\psi_{\mathrm{pd}}\right)$ values (around $-0.4 \mathrm{MPa}$ ) while FI vines, showed $\psi_{\mathrm{pd}}$ around $-0.2 \mathrm{MPa}$ during the growing season. NI showed the lowest $\psi_{\mathrm{pd}}$, reaching -0.6 MPa in Moscatel and $-0.8 \mathrm{MPa}$ in Castelão, at the end of growing season. Water status of PRD vines remained closer to FI than DI, especially at midday. Photosynthetic rates and fluorescence parameters of the deficit irrigation treatments (PRD and DI) did not show significant differences from FI vines, for most of the season. In Moscatel, although PRD generally showed $g_{\mathrm{s}}$, relative stomatal limitation (RSL) and intrinsic water use efficiency $\left(A / g_{\mathrm{s}}\right)$ values closer to NI than DI, most of the differences between PRD and DI were not statistically significant. Our results showed a stability of the photosynthetic machinery in grapevines under low-to-moderate water availabilities, as demonstrated by the maintenance of the activity of three Calvin Cycle enzymes and of the $V_{\text {cmax }}$ values. However, a decline in $J_{\max }$ was observed in NI vines, that can be a result either of a decrease in ATP production or, alternatively, of decreased mesophyll conductance to $\mathrm{CO}_{2}$ diffusion. In general terms, stomatal limitation of photosynthesis is likely to be dominant in non-irrigated plants. Deficit irrigation had no negative impact on $\mathrm{CO}_{2}$ assimilation, despite less water application than in full-irrigation. Differences among varieties may be related to differences in sensitivity of stomata, shoot growth and/or the interaction between rootstock and cultivar to soil water availability.
\end{abstract}

(C) 2004 Elsevier B.V. All rights reserved.

Keywords: Fluorescence; Gas exchange; Irrigation; Partial rootzone drying; Vitis vinifera; Water stress

\footnotetext{
* Corresponding author. Tel.: +351 213653415; fax: +351 213635031.

E-mail address: mchaves@isa.utl.pt (M.M. Chaves).
} 


\section{Introduction}

Water deficit is one of the most important environmental factors inhibiting photosynthesis, growth and production under field conditions in the Mediterranean (Chaves et al., 2002). Many horticultural crops, including grapevines, rely on irrigation water during drought periods because rainfall occurs primarily during the dormant season, with subsequent vine growth being dependent upon stored soil water. However, the use of irrigation has been considered a controversial practice in traditional viticulture, since excessive soil water availability can cause significant reductions in berry colour and composition (Jackson and Lombard, 1993).

A key to improve winegrape quality in irrigated vineyards is to achieve an appropriate balance between vegetative and reproductive development, as an excess of shoot vigour may have undesirable consequences for fruit composition (McCarthy, 1997). A mild water stress maintained through deficit irrigation may reduce vine vigour and competition for carbohydrates by growing tips, as well as promoting a shift in the partition of photoassimilates and secondary metabolites towards reproductive tissues. These changes in plant metabolism by mild water stress may increase the quality of the fruit and wine produced (Matthews and Anderson, 1988, 1989). The deliberate restriction of irrigation water may, therefore, be a legitimate management strategy to manipulate crop water use and this is embodied in the technique known as regulated deficit irrigation (RDI) (Boland et al., 1993; Alegre et al., 1999; Dry et al., 2001). However, accurate monitoring of both vine and soil moisture status is required, and RDI may also result in changes to specific characteristics such as the size of grape berries (McCarthy, 1997).

A new irrigation technique called partial rootzone drying (PRD) has been used in commercial vineyards in Australia. PRD irrigation in grapevines has been shown to increase water use efficiency and decrease vegetative vigour without significantly reducing crop yield and berry sizes (Loveys et al., 2000). In PRD, a percentage of crop evapotranspiration is applied in alternate sides of the vine, allowing part of the root system to be always in contact with drying soil, while the other half is in contact with wet soil. The beneficial effects of PRD are hypothesised to be due to the reduction of stomatal conductance and growth by chemical signals, possibly abscisic acid (ABA) synthesized by the roots in the drying soil zone and transported to the leaves in the transpiration stream (Loveys, 1984; Zhang and Davies, 1989a, 1989b).

Several studies have reported the effects of PRD on stomatal conductance, ABA in leaves and xylem, shoot and root growth rate (Loveys, 1984; Loveys et al., 2000; Stoll et al., 2000; Dry et al., 2000a, 2000b; Liu et al., 2001; dos Santos et al., 2003). Detailed physiological responses of grapevine to PRD and other deficit irrigation under natural field conditions have not received much attention. In previous studies, we have shown in cultivar Moscatel that leaf stomatal conductance, when measured under field conditions, but controlling $\mathrm{CO}_{2}$, light and temperature in the leaf cuvette, was more reduced under PRD than in an irrigation treatment where the same amount of water was given to both sides of the root system (DI). However, in seasonal and diurnal courses of instantaneous measurements no large differences could be detected (de Souza et al., 2003), implying that the regulation is very subtle.

The knowledge of the mechanisms that regulate grapevine photosynthesis under different water regimes is of great interest to understand the key factors that regulate plant water use efficiency and ultimately grape yield and quality while saving water. In the present work we did a detailed characterization of the photosynthetic carbon assimilation, stomatal conductance and plant water status under field conditions in two cultivars with distinct vigour and berry characteristics. Plants were subjected to PRD and DI irrigation systems and compared with full irrigation and the traditional rainfed conditions in the area.

\section{Materials and methods}

\subsection{Plant material and location}

The experiment was conducted in a commercial vineyard located $70 \mathrm{~km}$ south-east of Lisbon, at the Centro Experimental de Pegões. The climate is Mediterranean, with hot, dry summers and mild winters. The soil is derived from podzols, with a sandy surface layer $(0.6-1.0 \mathrm{~m})$ and clay at $1 \mathrm{~m}$ depth. The 
two varieties of Vitis vinifera L. studied were Moscatel (syn. Muscat of Alexandria), a vigorous and productive white variety used for wine and table grapes, and Castelão, an early season red wine variety (dos Santos et al., 2003). Both were grafted on 1103 Paulsen rootstock in 1997 and 1996, respectively. The grapevines were spaced $2.5 \mathrm{~m}$ between rows and $1.0 \mathrm{~m}$ within rows and trained on a vertical trellis with a pair of movable foliage wires for upwards shoot positioning. The vines were spur pruned on a bilateral Royat Cordon ( $\sim 16$ buds per vine).

\subsection{Irrigation and experimental design}

Irrigation water was applied with drip emitters ( $4 \mathrm{~L} \mathrm{~h}^{-1}$ for FI and PRD and $2 \mathrm{~L} \mathrm{~h}^{-1}$ for DI), two per vine, positioned $30 \mathrm{~cm}$ from the vine trunk (out to both sides of the rows), and distributed in both sides of root system. The water was supplied according to the crop evapotranspiration $\left(\mathrm{ET}_{\mathrm{c}}\right)$ calculated from the evaporation of a Class A pan and corrected with the crop coefficients $\left(K_{\mathrm{c}}\right)$ proposed by Prichard $(1992)$. The irrigation treatments were: rain fed non-irrigated (NI); partial rootzone drying (PRD, 50\% of the $\mathrm{ET}_{\mathrm{c}}$ was supplied to only one side of the root system, alternating sides each 15 days, approximately) deficit irrigated (DI, $50 \%$ of the $\mathrm{ET}_{\mathrm{c}}$ was supplied to both sides of the vine); full irrigated (FI, $100 \%$ of the $\mathrm{ET}_{\mathrm{c}}$ was supplied to both the sides of the root system). Irrigation was applied twice per week since the beginning of berry development (June) until harvest (August and September). Cumulative rainfall for the experimental period was $110 \mathrm{~mm}$ in 2002 .

\subsection{Water relations}

Pre-dawn $\left(\psi_{\mathrm{pd}}\right)$ and midday $\left(\psi_{\mathrm{md}}\right)$ leaf water potential of six sun exposed and fully expanded leaves per treatment were measured with a Scholander-type pressure chamber (Model 1000; PMS Instrument Co., Corvallis, OR, USA), from the beginning of berry development until harvest.

\subsection{Gas exchange and chlorophyll fluorescence}

Daily net $\mathrm{CO}_{2}$ assimilation (A), stomatal conductance $\left(g_{\mathrm{s}}\right)$, and $A-C_{\mathrm{i}}$ response curves were measured on sun-exposed and recently fully mature leaves, using a portable Li-6400 IRGA (Licor, Lincoln, Nebraska, USA) with four to eight replications per treatment for instantaneous measurements and four replications per treatment for $A-C_{\mathrm{i}}$ response curves. For $A / C_{\mathrm{i}}$ response curves the leaf chamber temperature was kept at $25^{\circ} \mathrm{C}$, photosynthetic photon flux density (PPFD) of $1200 \mu \mathrm{mol}$ photons $\mathrm{m}^{-2} \mathrm{~s}^{-1}$ and relative humidity of $60-70 \%$. The maximum rate of Rubisco carboxylation $\left(V_{\mathrm{cmax}}\right)$, maximum electron transport capacity at saturating light $\left(J_{\max }\right)$ and the rate of triose-P utilization (TPU) were obtained by fitting the model of Farquhar et al. (1980) with modifications by Sharkey (1985) to $A / C_{\mathrm{i}}$ response curves as described by Maroco et al. (2002). The net $\mathrm{CO}_{2}$ assimilation biochemical model for $\mathrm{C}_{3}$ plants of Farquhar et al. (1980) can be written as:

$A=V_{\mathrm{c}}-0.5 V_{\mathrm{o}}-R_{\mathrm{d}}=V_{\mathrm{c}}\left(1-\frac{0.5 O}{\tau C_{\mathrm{i}}}\right)-R_{\mathrm{d}}$

where $V_{\mathrm{c}}$ and $V_{\mathrm{o}}$ are the rates of carboxylation and oxygenation of Rubisco, $R_{\mathrm{d}}$ is the mitochondrial respiration, $O$ and $C_{\mathrm{i}}$ are the oxygen and $\mathrm{CO}_{2}$ partial pressures in intercellular spaces, respectively and $\tau$ is the Rubisco specificity factor for $\mathrm{CO}_{2} / \mathrm{O}_{2}$ factor. According to Farquhar et al. (1980) with modifications by Sharkey (1985), $V_{c}$ is a minimum function of the carboxylation rates limited by either (i) kinetic properties and amount of Rubisco $\left(W_{\mathrm{c}}\right)$; (ii) the rate of RuBP regeneration $\left(W_{\mathrm{j}}\right)$; or (iii) the availability of inorganic phosphate $\left(W_{\mathrm{p}}\right)$. That is $V_{\mathrm{c}}=\operatorname{minimum}\left\{W_{\mathrm{c}}, W_{\mathrm{j}}, W_{\mathrm{p}}\right\}$.

The rate of carboxylation limited by the amount and kinetic properties of Rubisco is given by:

$$
W_{\mathrm{c}}=\frac{V_{\mathrm{cmax}} C_{\mathrm{i}}}{C_{\mathrm{i}}+K_{\mathrm{c}}\left(1+O / K_{\mathrm{o}}\right)}
$$

where $V_{\text {cmax }}$ is the maximum rate of carboxylation, while $K_{\mathrm{c}}$ and $K_{\mathrm{o}}$ are the Michaelis constants for the carboxylation and oxygenation processes, respectively.

The rate of carboxylation limited by the regeneration of RuBP is a function of the rate of electron transport given by:

$$
W_{\mathrm{j}}=\frac{J C_{\mathrm{i}}}{4\left(C_{\mathrm{i}}+O / \tau\right)}
$$

where it is assumed that four electrons are enough to generate the three ATP and two NADPH required in 
the Calvin cycle to regenerate RuBP, and $J$ is the rate of electron transport trough PSII given by:

$J=\frac{\alpha I}{\sqrt{1+\alpha^{2} I^{2} / J_{\max }^{2}}}$

where $\alpha$ is the fraction of incident light that is converted into electrons and $J_{\max }$ is the maximum, light saturated, rate of electron transport.

Finally, the rate of carboxylation limited by inorganic phosphate availability inside the chloroplast is given by:

$W_{\mathrm{p}}=3 \mathrm{TPU}+\frac{V_{\mathrm{c}} O}{2 C_{\mathrm{i}} \tau}$

where TPU is the rate of triose-P utilization (for sucrose and starch synthesis) (Sharkey, 1985). Michaelis-Menten constants $\left(K_{\mathrm{c}}\right.$ and $\left.K_{\mathrm{o}}\right), \alpha, \tau$ and temperature dependence of the model parameters were corrected as described by Harley et al. (1992). According to these authors, the temperature dependence of $K_{\mathrm{c}}, K_{\mathrm{o}}, \alpha, \tau$ is described by an exponential function of the type parameter $=\exp \left[c-\Delta H_{\mathrm{a}} / R T\right]$, where $c$ is a scaling constant characteristic for each parameter, $\Delta H_{\mathrm{a}}$ is the activation energy for the parameter, $R$ is the ideal gas-constant, and $T$ is the leaf temperature in degrees Kelvin. For details of constants used to parameterise the photosynthetic model, see Table $1 . V_{\text {cmax }}$ and $R_{\mathrm{d}}$ were estimated by fitting the model to measured $A-C_{\mathrm{i}}$ data for $C_{\mathrm{i}}$ less than $20 \mathrm{~Pa}$ because, in this $C_{\mathrm{i}}$ range $V_{\mathrm{c}}$ is limited only by $W_{\mathrm{c}}$, if light is saturating, as it was in this case. Finally, $J_{\max }$ and TPU were estimated by fitting the model, with previously estimated $V_{\text {cmax }}$ and $R_{\mathrm{d}}$, to the complete $A-$ $C_{\mathrm{i}}$ data using a non-linear curve fitting routine from SAS (SAS Institute, Cary, North Carolina, USA).

The limitation to photosynthesis imposed by closed stomata was calculated from $A / C_{\mathrm{i}}$ response curves using the equation $\mathrm{RSL}=\left(\left(A_{C_{\mathrm{i}}=35 \mathrm{~Pa}}-A_{C_{\mathrm{a}}=35 \mathrm{~Pa}}\right) /\right.$ $\left.A_{C_{\mathrm{i}}=35 \mathrm{~Pa}}\right) \times 100 \%$, where RSL is the relative stomatal limitation, $A_{C_{\mathrm{i}}=35 \mathrm{~Pa}}$ is the net $\mathrm{CO}_{2}$ assimilation at intercellular $\mathrm{CO}_{2}$ of $35 \mathrm{~Pa}$, and $A_{C_{\mathrm{a}}}=35 \mathrm{~Pa}$ is the net $\mathrm{CO}_{2}$ assimilation at ambient $\mathrm{CO}_{2}$ of $35 \mathrm{~Pa}$. Estimates of $A_{C_{\mathrm{i}}=35 \mathrm{~Pa}}$ were obtained from previously fitted Eq. (1) to $A / C_{\mathrm{i}}$ (or $C_{\mathrm{a}}$ ) data.

Chlorophyll a fluorescence was measured from berry set to harvest using a Mini Pam fluorometer $(\mathrm{H}$. Walz, Effeltrich, Germany), in the same leaves used for the daily courses of gas exchange. The PSII photochemical efficiency $\left(\Phi_{\text {PSII }}\right)$ was calculated as $\Phi_{\text {PSII }}=$ $\left(F_{\mathrm{m}}^{\prime}-F_{\mathrm{s}}\right) / F_{\mathrm{m}}^{\prime}$ and non-photochemical quenching (NPQ) calculated as $\mathrm{NPQ}=\left(F_{\mathrm{m}}-F_{\mathrm{m}}^{\prime}\right) / F_{\mathrm{m}}^{\prime}$. The electron transport rate (ETR) was calculated as $\mathrm{ETR}=\Delta F / F_{\mathrm{m}}^{\prime} \times \mathrm{PPFD} \times 0.5 \times 0.84($ Bjökman and Demmig, 1987). Measurements were done at two weeks intervals from beginning of berry development until harvest, during the 2002 growing season.

\subsection{Enzyme assays}

For determination of enzyme activity six discs $\left(3.56 \mathrm{~cm}^{2}\right)$ per plant (four plants per treatment) were harvested in the light, frozen in liquid $\mathrm{N}_{2}$ and stored $-80{ }^{\circ} \mathrm{C}$ until assay. The frozen leaf discs were ground to a fine slurry in $1.5 \mathrm{ml}$ of an extraction solution

Table 1

List of constant model parameters used to estimate $V_{\mathrm{cmax}}, J_{\max }$, TPU and $R_{\mathrm{d}}{ }^{\mathrm{a}}$

\begin{tabular}{|c|c|c|c|c|}
\hline Parameter & Units & Temperature parameters & Values & Units \\
\hline \multirow[t]{2}{*}{$K_{\mathrm{c}}$} & $\mathrm{Pa} \mathrm{CO}_{2}$ & $c\left(K_{\mathrm{c}}\right)$ & 35.79 & - \\
\hline & & $\Delta H_{\mathrm{a}}\left(K_{\mathrm{c}}\right)$ & 80.47 & $\mathrm{~kJ} \mathrm{~mol}^{-1}$ \\
\hline \multirow[t]{2}{*}{$K_{\mathrm{o}}$} & $\mathrm{kPaO}_{2}$ & $c\left(K_{\mathrm{o}}\right)$ & 9.59 & - \\
\hline & & $\Delta H_{\mathrm{a}}\left(K_{\mathrm{o}}\right)$ & 14.51 & $\mathrm{~kJ} \mathrm{~mol}^{-1}$ \\
\hline \multirow[t]{2}{*}{$\tau$} & - & $c(\tau)$ & -3.9489 & - \\
\hline & & $\Delta H_{\mathrm{a}}(\tau)$ & -28.99 & $\mathrm{~kJ} \mathrm{~mol}^{-1}$ \\
\hline$T$ & $\mathrm{~K}$ & - & 298 & - \\
\hline$R$ & $\mathrm{~kJ} \mathrm{~K}^{-1} \mathrm{~mol}^{-1}$ & - & 0.00831 & - \\
\hline$\alpha$ & mol electrons per mol photons & - & 0.18 & - \\
\hline PPFD & $\mu \mathrm{mol}$ photons $\mathrm{m}^{-2} \mathrm{~s}^{-1}$ & - & 1200 & - \\
\hline$O$ & $\mathrm{~Pa}$ & - & 20580 & - \\
\hline
\end{tabular}

$K_{\mathrm{c}}$ and $K_{\mathrm{o}}$, Michaelio-Menten constants for $\mathrm{CO}_{2}$ and $\mathrm{O}_{2}$, respectively; $\tau$, Rubisco specificity factor for $\mathrm{CO}_{2} / \mathrm{O}_{2} ; T$, leaf temperature; $R$, universal gas constant; $\alpha$, efficiency of light energy conversion on an incident light basis; PPFD, incident light; $O$, oxygen concentration.

${ }^{\text {a }}$ Data from Harley et al. (1992). 
containing $200 \mathrm{mM}$ Tris- $\mathrm{HCl}(\mathrm{pH} \quad 8.0), 10 \mathrm{mM}$ $\mathrm{MgCl}_{2}, 10 \mathrm{mM} \mathrm{NaHCO}{ }_{3}, 10 \mathrm{mM} \beta$-mercaptoethanol, $2 \mathrm{mM}$ dithiothreitol (DTT), $2 \%$ triton X-100, 4\%(v/v) 'Complete-protease inhibitor cocktail with EDTA', $10 \%$ polyvinylpolypyrrolidone, and $10 \%$ glycerol. The enzymatic activities of glyceraldehyde-3-phosphate dehydrogenase (G3PDH; EC 1.2.1.13), ribulose-5-phosphate kinase (Ru5PK; EC 2.7.1.19) and stromal fructose-1,6-biphospahte phosphatase (FruBPase; EC 3.1.3.11) were measured spectrophotometrically by following the oxidation of NADH at $340 \mathrm{~nm}$. The activity of G3PDH was measured by adding $20 \mu \mathrm{L}$ of leaf extract in $1 \mathrm{~mL}$ of reaction mixture containing $100 \mathrm{mM}$ Tris- $\mathrm{HCl} \mathrm{pH} 8.0 ; 2 \mathrm{mM}$ $\mathrm{MgCl}_{2} ; 1 \mathrm{mM}$ EDTA; $0.4 \mathrm{mM}$ NADH; $6 \mathrm{mM} 3-$ phosphoglyceric acid (PGA); 20 units 3-phosphoclyceric phosphokinase (PGK). The reaction was started with $5 \mathrm{mM}$ ATP. The activity of Ru5PK was measured, after preincubation for $15 \mathrm{~min}$, by adding $20 \mu \mathrm{L}$ of leaf extract in $1 \mathrm{~mL}$ of reaction mixture containing $100 \mathrm{mM}$ Tris- $\mathrm{HCl} \mathrm{pH} 8.0 ; 8 \mathrm{mM} \mathrm{MgCl}_{2}$; 40 mM KCl; 1 mM PEP; 10 mM ATP; 1 mM NADH; 20 mM DTT; 8 units pyruvate kinase; 10 units lactate dehydrogenase; and 5 units phosphoriboisomerase. The reaction was started adding $5 \mathrm{mM}$ Ribose-5Phosphate. For the FruBPase assay, $50 \mu \mathrm{L}$ of leaf extract was added into $1 \mathrm{ml}$ reaction mixture containing $200 \mathrm{mM}$ Tris- $\mathrm{HCl} \mathrm{pH} 8.0 ; 10 \mathrm{mM} \mathrm{MgCl}_{2} ; 10 \mathrm{mM}$ DTT, 1 mM EDTA, 0.4 NADP; 4 units glucose-6phosphate isomerase; 2 units glucose-6-phosphate dehydrogenase. The reaction was started with $1 \mathrm{mM}$ fructose-1,6-bisphospate. The enzymatic activities were expressed in $\mu \mathrm{mol}$ of $\mathrm{NADH}$ per unit leaf area.

\subsection{Leaf nitrogen content and vine vigour}

Similar leaves to those used for photosynthesis measurements were harvested for the analysis of nitrogen. The leaves (four leaves per treatment) were harvested in different dates throughout the growing season. Total nitrogen content of the leaves were measured by the Kjeldahl method, using leaf material that had been dried at $80{ }^{\circ} \mathrm{C}$ and powdered.

In this study the vine vigour was estimated by the pruning weight. At winter pruning, shoot number and weight were taken to determinate the shoot weight per vine.

\subsection{Statistical data analyses}

Two-way factorial analyses of variance (ANOVA), with sampling time and treatments as main factors, was used to test the main effects and factor interactions on $\psi_{\mathrm{pd}}, \psi_{\mathrm{md}}$, gas exchange and fluorescence parameters. One-way ANOVA was used to test the treatment effects on enzymes, nitrogen contents and pruning weight. Significant differences between treatments means were evaluated with Tukey's HSD tests with $\alpha=0.05$ using the "Statistica" software (Version 5.0 StatSoft, Tulsa, OK, USA). All measurements shown are the mean \pm S.E.

\section{Results}

\subsection{Environmental conditions and plant water status}

Fig. 1 shows the rainfall and average temperature during 2002 and the 30-year average for the region. The amount of rainfall during spring and at the end of experimental period (September) was higher in 2002 as compared to the 30-year average. On the other hand, the average temperature followed the same pattern as the 30 -year average, ranging between 20 and $22.5{ }^{\circ} \mathrm{C}$ during the summer. During the measurements period, the maximal temperature (around $35^{\circ} \mathrm{C}$ ) was recorded at the middle of June and the end of July (Fig. 2).

The vine water status was influenced by the irrigation treatments. In both cultivars, PRD and DI showed intermediate pre-dawn leaf water potential

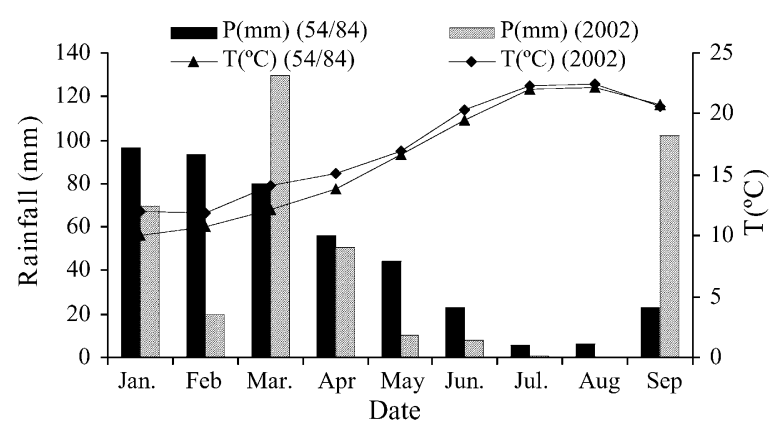

Fig. 1. Total rainfall (bars) and monthly mean air temperature (lines) at the experimental site during the 2002 season and average values of 30 years (1954-1984). 


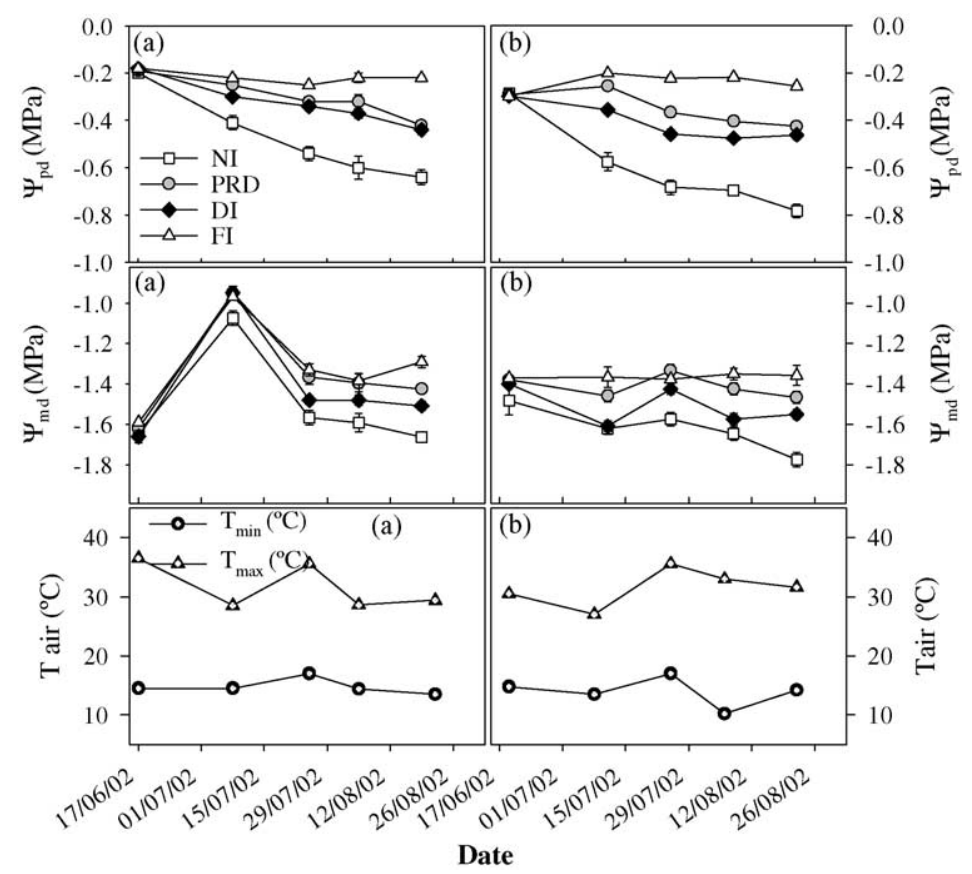

Fig. 2. Seasonal evolution of leaf water potential at pre-dawn $\left(\psi_{\mathrm{pd}}\right)$ and at midday $\left(\psi_{\mathrm{md}}\right)$ and minimal $\left(T_{\min }\right)$ and maximum $\left(T_{\max }\right)$ temperatures in Moscatel (a) and Castelão (b) recorded during the days of measurements. Values of leaf water potential are mean \pm S.E.

$\left(\psi_{\text {pd }}\right)$ values (around $\left.-0.4 \mathrm{MPa}\right)$ as compared to NI and FI vines. However, in Castelão, PRD vines showed significantly higher values than DI vines during July. The NI vines showed increasing differences in $\psi_{\mathrm{pd}}$ from July onwards as compared with the other treatments. At the end of the growing season, the $\psi_{\mathrm{pd}}$ in NI vines reached $-0.6 \mathrm{MPa}$ in Moscatel and -0.8 MPa in Castelão. FI vines showed an almost constant $\psi_{\text {pd }}$ (around $-0.2 \mathrm{MPa}$ ) throughout the growing season in both cultivars. The midday leaf water potential $\left(\psi_{\mathrm{md}}\right)$ followed a pattern similar to the $\psi_{\mathrm{pd}}$. The $\psi_{\mathrm{md}}$ in PRD vines was in general closer to FI vines than DI vines during growing season. However, there were no statistically differences between PRD and DI in most of the sampled dates in both cultivars.

\subsection{Seasonal evolution of gas exchange and chlorophyll fluorescence derived parameters}

The ANOVA test revealed a significant effect $(P<0.01)$ of irrigation treatments in gas exchange and fluorescence parameters recorded in both cultivars (Fig. 3). During the growing season, the highest reductions in photosynthesis $(A)$ and stomatal con- ductance $\left(g_{\mathrm{s}}\right)$ occurred in NI vines. The effect of PRD and DI was more pronounced in $g_{\mathrm{s}}$ than $A$. Although there were no statistically differences between PRD and DI, the values of $g_{\mathrm{s}}$ in PRD were closer to NI than DI vines at the middle of growing season, especially in Moscatel. In Castelão, FI vines also showed a reduction in gas exchange at the end of growing season, whereas in Moscatel the values of $A$ and $g_{\text {s }}$ were maintained almost constant (around $12 \mu \mathrm{mol} \mathrm{CO} \mathrm{m}^{-2} \mathrm{~s}^{-1}$ and $0.25 \mathrm{~mol} \mathrm{H}_{2} \mathrm{O} \mathrm{m}^{-2} \mathrm{~s}^{-1}$, respectively).

The quantum yield of PSII reaction centres $\left(\Phi_{\text {PSII }}\right)$ in Moscatel leaves were not affected the irrigation treatments during the growing season. However, in Castelão, NI vines showed a decrease in $\Phi_{\mathrm{PSII}}$ of $47 \%$ as compared to FI vines at the middle of the growing season. In both cultivars, there was no indication of permanent photoinhibition, as demonstrated by predawn $F_{\mathrm{v}} / F_{\mathrm{m}}$ values always close to 0.8 .

In Moscatel, there was an increase (around 35\%) of intrinsic water use efficiency $\left(A / g_{\mathrm{s}}\right)$ in PRD and NI vines as compared to FI vines. Although the $A / g_{\mathrm{s}}$ in PRD was closer to NI values, it was not statistically significant different from DI. In Castelão, there were 


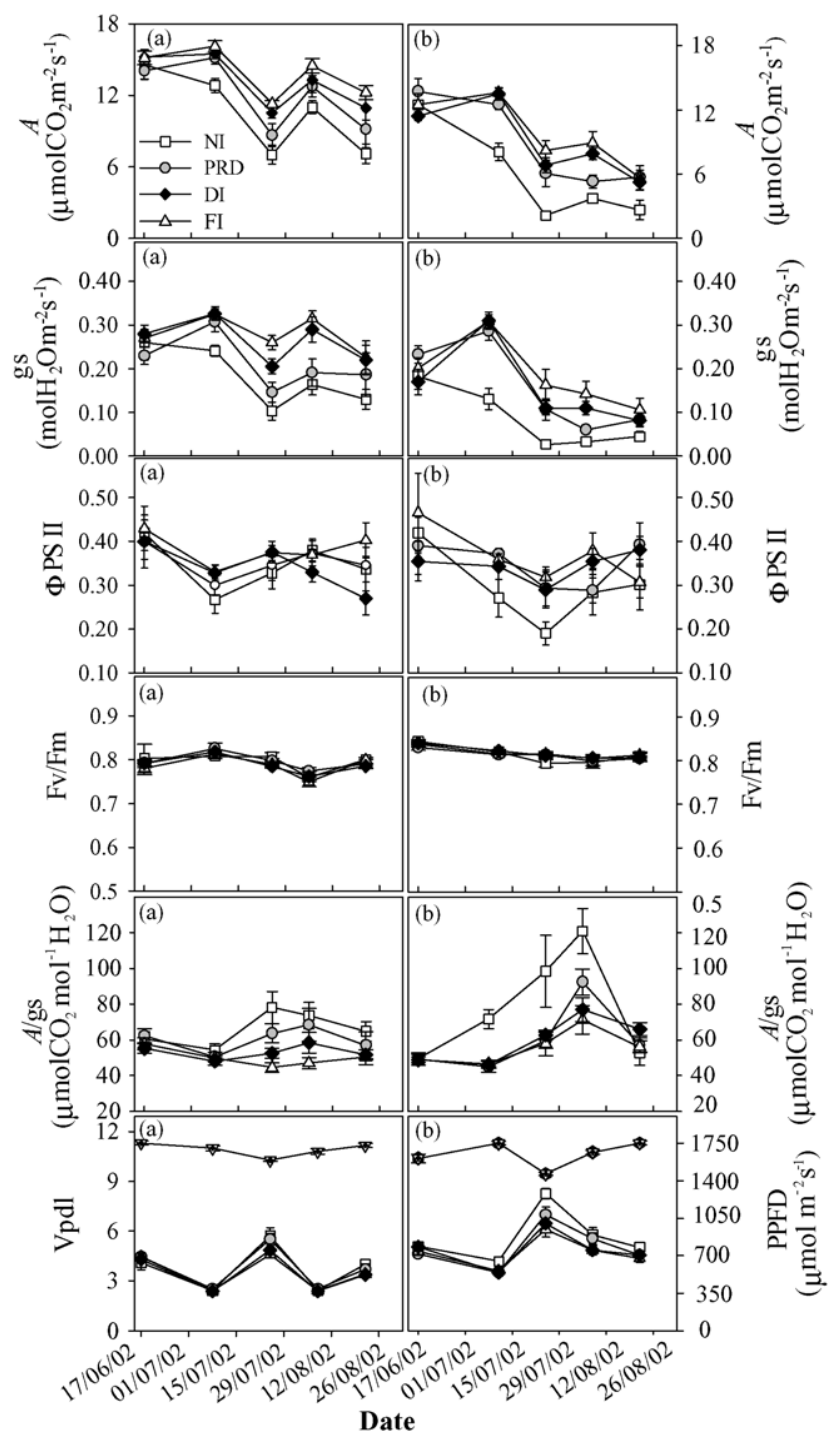

Fig. 3. Seasonal trends at midday of photosynthesis $(A)$, stomatal conductance $\left(g_{\mathrm{s}}\right)$, quantum yield of PSII $\left(\Phi_{\mathrm{PSII}}\right)$, efficiency of excitation capture by open PSII in dark-adapted leaves $\left(F_{\mathrm{v}} / F_{\mathrm{m}}\right)$, intrinsic water use efficiency $\left(A / g_{\mathrm{s}}\right)$, leaf-to-air vapour pressure defict $(\mathrm{Vpdl})$ and photosynthetic photon flux density (PPFD) in cultivars Moscatel (a) and Castelão (b). Values are the mean \pm S.E.

statistically significant differences only between irrigated (FI, DI, PRD) treatments and the nonirrigated treatment $(\mathrm{NI})$.

During the growing season, the highest values of leaf-to-air vapour pressure deficit (Vpdl) occurred on 25 July for both cultivars. In Moscatel, NI and PRD vines showed higher values of Vpdl (around 5.5-5.7) than DI and FI vines (around 4.6-4.8). In Castelão, NI vines reached a value near to $8, \mathrm{PRD}$ and DI vines showed the intermediate values (around 6.4-6.9) and FI, the lowest values (6). However, there were no significant differences between DI and PRD vines in both cultivars.

There was a significant correlation of $A$ and $g_{\mathrm{s}}$ with pre-dawn water potential (Fig. 4). However, the best correlations were obtained using midday values of $A$ and $g_{\mathrm{s}}$. The dependence of $A$ and $g_{\mathrm{s}}$ on $\psi_{\mathrm{pd}}$ was slightly higher in Castelão than in Moscatel as shown by the 


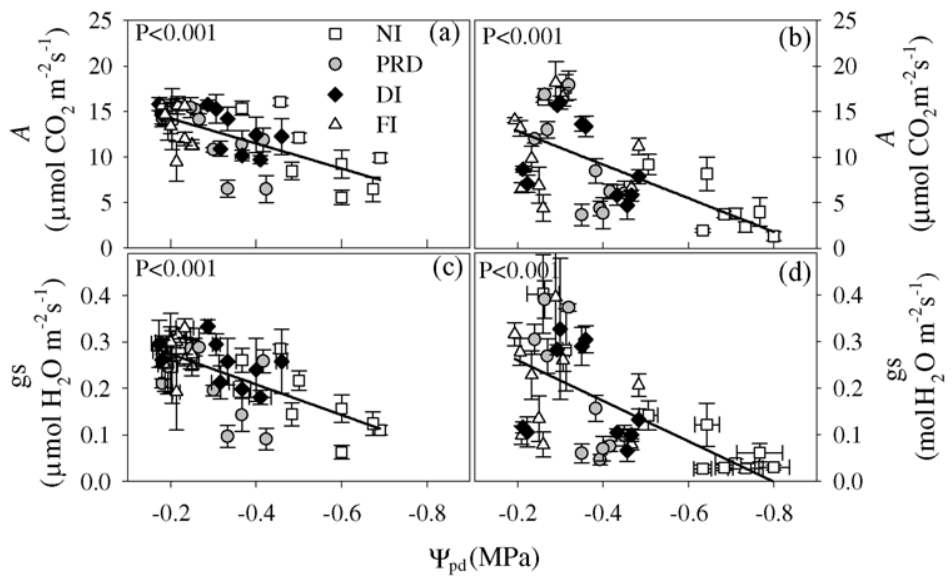

Fig. 4. Dependence of photosynthesis of Moscatel (a) $\left(y=16.97+13.74 x, R^{2}=0.41\right)$ and Castelão (b) $\left(y=16.55+18.45 x, R^{2}=0.37\right)$ and of stomatal conductance of Moscatel (c) $\left(y=0.34+0.32 x, R^{2}=0.44\right)$ and Castelão (d) $\left(y=0.34+0.41 x, R^{2}=0.38\right)$ on pre-dawn leaf water potential $\left(\psi_{\mathrm{pd}}\right)$. Values are mean \pm S.E. Measurements were taken throughout the growing season at midday.

slope of the equation regression (although the differences were not statistically significant). For $\psi_{\mathrm{pd}}$ around $-0.6 \mathrm{MPa}, A$ was reduced by $48 \%$ and $g_{\mathrm{s}}$ by $56 \%$ in Moscatel, whereas in Castelão, $A$ was reduced by $67 \%$ and $g_{\mathrm{s}}$ by $74 \%$. Despite the higher reductions in Castelão, there were no significant differences between the two varieties due to the large variability observed. According to the regression equation, the maximum $A$ and $g_{\mathrm{s}}$ (extrapolating at $\left.\psi_{\mathrm{pd}}=0.0\right)$ were similar for both cultivars.

The coefficients of determination $\left(R^{2}\right.$, indicating the proportion of the variability in $A$ that is explained by $g_{\mathrm{s}}$ ) between $A$ and $g_{\mathrm{s}}$ were high in both cultivars (0.81 and 0.91) (Fig. 5), which suggest a strong regulation of photosynthesis by stomatal aperture, or at least a co-regulation. Both cultivars showed also significant correlation of $A / g_{\mathrm{s}}$ and ETR/A with $g_{\mathrm{s}}$ $(P<0.001)$. However in $A / g_{\mathrm{s}}$, Moscatel showed a higher coefficient of determination (0.70) as compared to Castelão (0.48). The response of ETR/A to $g_{\mathrm{s}}$ showed that the increase of this ratio is higher in Castelão than Moscatel when stomatal conductance is close to zero.

\section{3. $A-C_{i}$ response curves}

In Fig. 6 are illustrated the maximum rate of Rubisco carboxylation $\left(V_{\mathrm{cmax}}\right)$, maximum electron transport capacity at saturating light $\left(J_{\max }\right)$, the rate of
triose-P utilization (TPU) and the relative stomatal limitation (RSL) estimated from $A / C_{\mathrm{i}}$ response curve. In both cultivars, there was no effect of the water treatments on $V_{\text {cmax }}$. In Moscatel, $J_{\max }$ decreased by $46 \%$ in NI vines as compared to FI vines that showed the highest values $\left(233 \mu \mathrm{mol} \mathrm{m}{ }^{-2} \mathrm{~s}^{-1}\right)$. PRD and DI vines showed the intermediate values around 203$219 \mu \mathrm{mol} \mathrm{m}^{-2} \mathrm{~s}^{-1}$. In Castelão, there were no significant differences among water treatment in $J_{\max }$.

In Moscatel, the TPU was reduced by $26 \%$ in NI and PRD vines as compared to FI vines, whereas the decrease of DI by $14 \%$ was not statistically significant. In Castelão, NI vines showed reductions in TPU of $36 \%$ in NI vines, whereas DI and PRD showed reductions by $18 \%$ as compared to FI vines.

There was an increase in RSL in NI and PRD vines as compared to DI and FI vines in Moscatel, whereas in Castelão, only in NI vines an increase in RSL was observed. In both cultivars, there were no significant differences between PRD and DI vines regarding the parameters estimated from $A-C_{\mathrm{i}}$ curves $\left(J_{\max }\right.$, TPU and RSL).

\subsection{Enzymatic activities and leaf nitrogen content}

The activity of some photosynthetic enzymes was also measured in Castelão and Moscatel in August during the ripening period (Fig. 7). The activities of G3PDH (a key enzyme in the reductive phase of the 


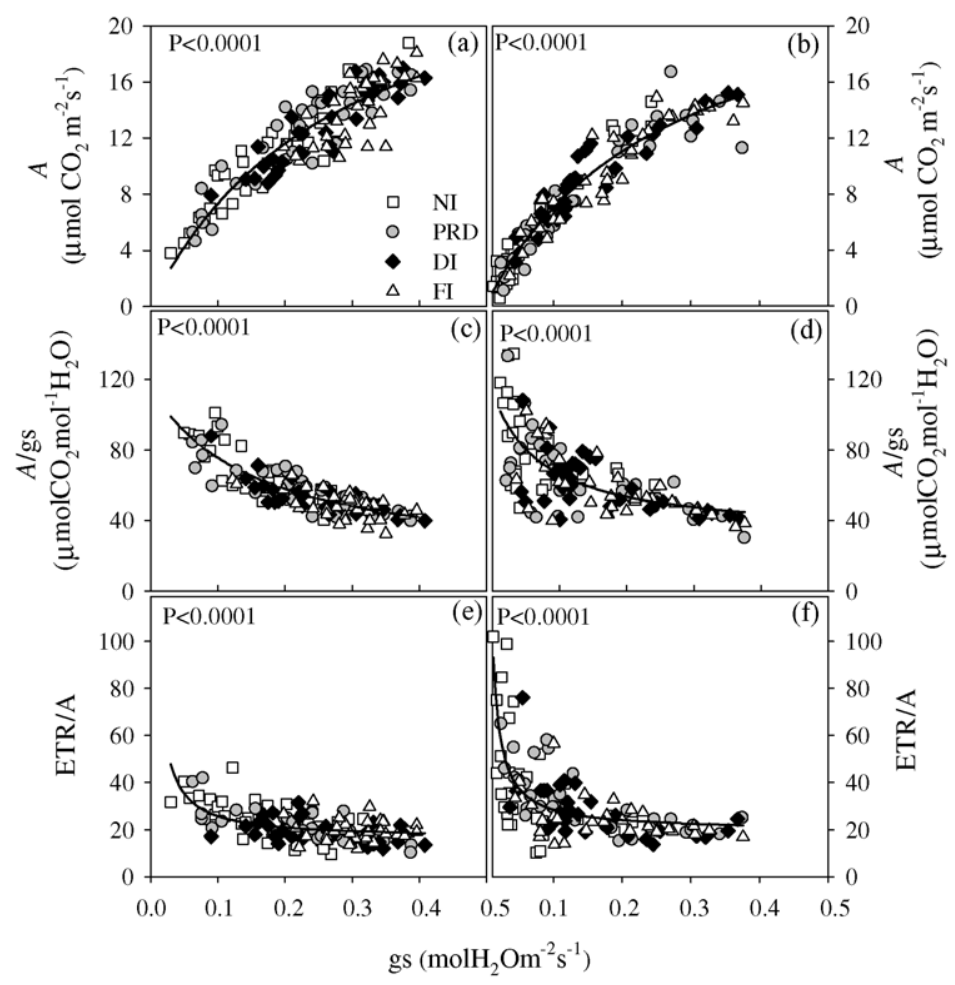

Fig. 5. Dependence on stomatal conductance of photosynthesis in Moscatel (a) $\left(y=28.02 x /(0.28+x), R^{2}=0.81\right)$ and Castelão (b) $(y=25.62 x /$ $\left.(0.26+x), R^{2}=0.91\right)$; of intrinsic water use efficiency $\left(A / g_{\mathrm{s}}\right)$ in Moscatel $(\mathrm{c})\left(y=12.80+16.45 /(0.156+x), R^{2}=0.70\right)$, and Castelão $(\mathrm{d})$ $\left(y=30.86+6.25 /(0.0759+x), R^{2}=0.48\right.$; and of the ratio ETR/A in Moscatel (e) $\left(y=16.17+0.96 / x, R^{2}=0.32\right)$ and Castelão (f) $\left(y=19.65+0.879 / x, R^{2}=0.48\right)$. Measurements were taken throughout the growing season at midday.

Calvin Cycle), FruBPase (a key enzyme in the utilization of triose-P) and Ru5PK (a key enzyme in the regenerative phase of the Calvin Cycle) were not affected significantly by the different water availability in both cultivars. No significant differences $(P>0.05)$ were observed in leaf $\mathrm{N}$ among treatments. These results suggest that there were no effects of the irrigation treatments on the biochemical processes associated with $\mathrm{CO}_{2}$ assimilation and triose-P utilization.

\subsection{Vine vigour}

In both cultivars, DI and FI vines showed the highest values of shoot biomass collected at pruning (Fig. 8). However, the statistically significant differences among irrigations treatments were only observed in Castelão. In this cultivar, there was a significant reduction $(36 \%)$ in pruning weight in NI and PRD as compared to DI and FI vines.

\section{Discussion}

The different water availability in the soil resulted in different vine water status and consequently had effects on carbon uptake during the growing season (Fig. 2). It is noteworthy that the water status at midday in PRD of both cultivars was much closer to FI as compared to DI vines, although the latter treatment received the same amount of water as PRD. This did not happen at predawn, where PRD and DI were much closer to each other. These results support the hypothesis underlying the PRD technique that partial root dehydration caused by alternating the sides of the irrigation, is controlling plant water status, possibly by a chemical signal travelling from the roots to shoots, leading to stomatal closure and therefore water conservation (Loveys et al., 2000; Stoll et al., 2000).

The values of stomatal conductance and midday water potential do agree with the hypothesis of more 


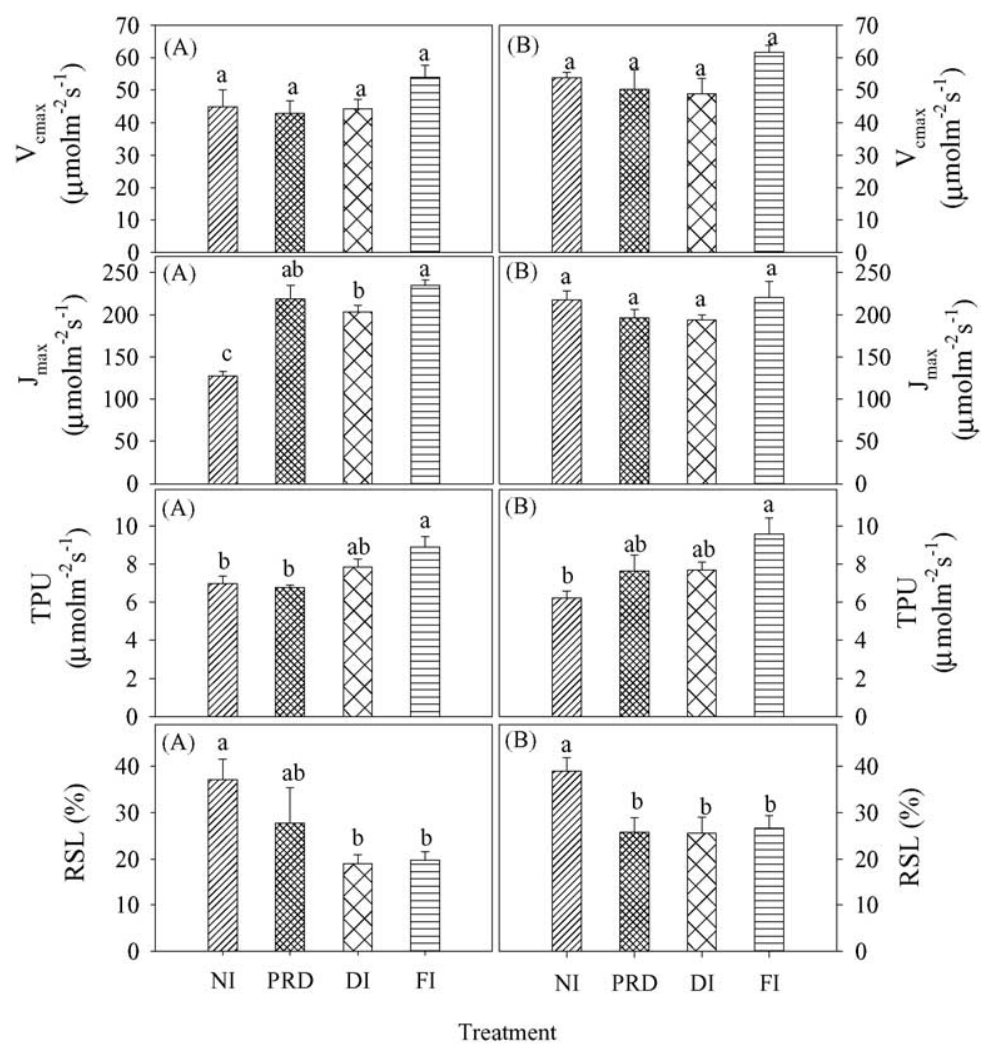

Fig. 6. Estimated model parameters $\left(V_{\mathrm{cmax}}, J_{\max }\right.$, TPU) and relative stomatal limitation (RSL) for the irrigation treatments in Moscatel (A) and Castelão (B) measured in August. Values are mean \pm S.E. Different letter suffixes show statistically significant differences $(P<0.05)$.

intense closure of stomata at midday in PRD vines as compared with DI, as observed in the seasonal course of $A$ and $g_{\mathrm{s}}$ (Fig. 3), mainly for the cultivar Moscatel. We observed in a previous work (de Souza et al., 2003) that under field conditions point measurements such as those given by leaf porometers, may not reveal stomatal control as effectively as other more integrated measurements such as stem sap flow or leaf $\delta^{13} \mathrm{C}$ discrimination. In addition, the decrease in leaf elongation without the detection of any reduction in stomatal conductance can occur, as showed by Saab and Sharp (1989). In our study the vine vigour was significantly reduced in NI and PRD as compared to DI and FI as showed by pruning weight in cv. Castelão (Fig. 8). In the same experiment, but in previous years (2000 and 2001), the inhibition of vegetative growth in PRD vines as compared with DI was also observed in both cultivars (dos Santos et al., 2003).
Increased stomatal limitation in NI and PRD as compared to DI and FI is also confirmed by RSL estimations from $A / C_{\mathrm{i}}$ curves (Fig. 6) and by the higher intrinsic water use efficiency, given by $A / g_{\mathrm{s}}$ in Moscatel (Fig. 3). Increased xylem sap ABA concentration was considered as a potential cause of the observed decrease in stomatal conductance as shown in several studies (Davies et al., 2000; Stoll et al., 2000; Liu et al., 2001). However, this response can vary among species as demonstrated by Fort et al. $(1997,1998)$ working with seedlings of young oak and Betula pendula, who did not find an increase of ABA concentration in xylem sap originated in the roots under PRD conditions. A chemical signal from dehydrating roots leading to a change in apoplastic ABA content in leaves may be responsible for increased stomatal closure under PRD (Holbrook et al., 2002). 


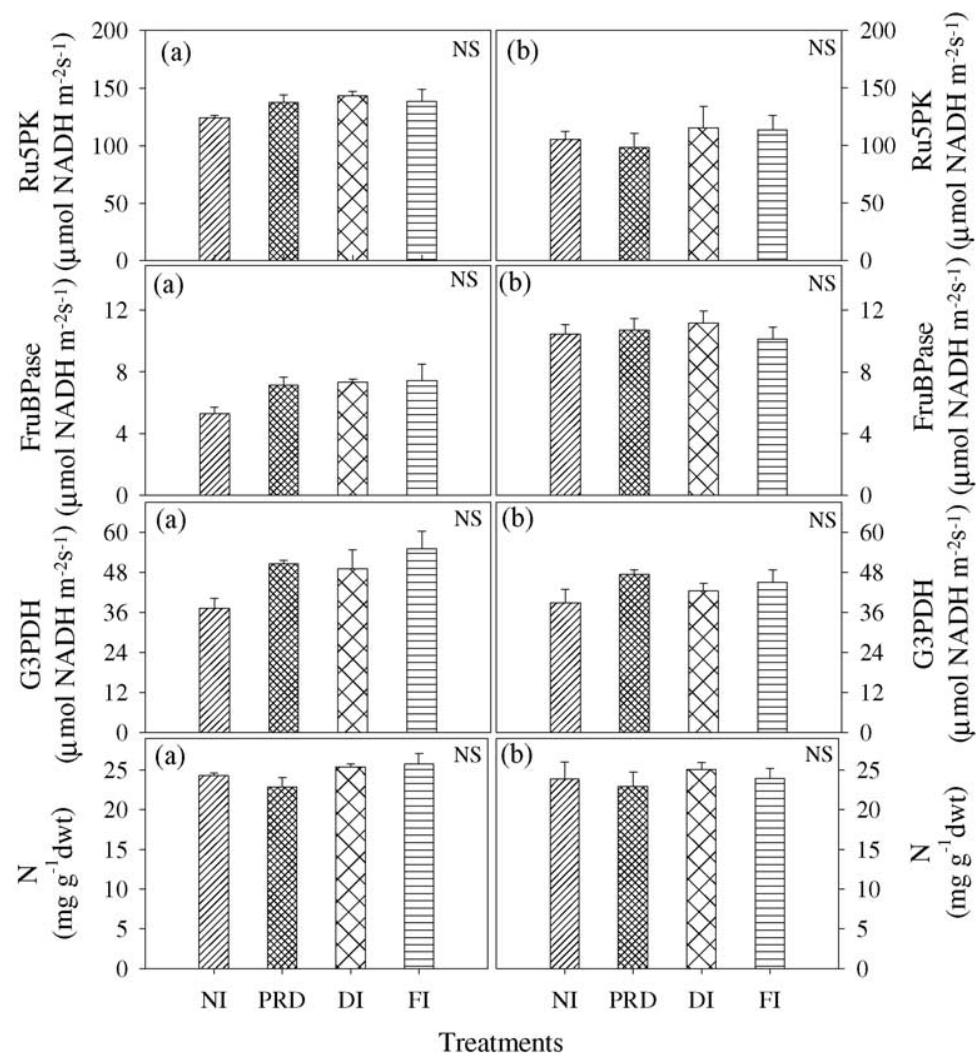

Fig. 7. In vitro activities of glyceraldehyde-3-phosphate dehydrogenase (G3PDH), ribulose-5-phosphate kinase (Ru5PK) and fructose-1,6biphosphate phosphatase (FruBPase) and leaf $\mathrm{N}$ contents $(\mathrm{N})$ on different water treatments in cultivars Moscatel (a) and Castelão (b) measured in August. Values are mean \pm S.E. NS: non-significant.

Although there was a decrease in stomatal conductance, the photosynthetic performance of PRD and DI was similar to FI vines as demonstrated by the seasonal evolution of $A$ (Fig. 3). The lowest photosynthetic rates obtained in NI vines of $\mathrm{cv}$.
Castelão were accompanied by reductions in $\Phi_{\text {PSII }}$ suggesting a down-regulation of photochemistry to match the decreased $\mathrm{CO}_{2}$ assimilation capacity under water stress conditions. In this cultivar, the reductions of photosynthesis observed in FI vines during the

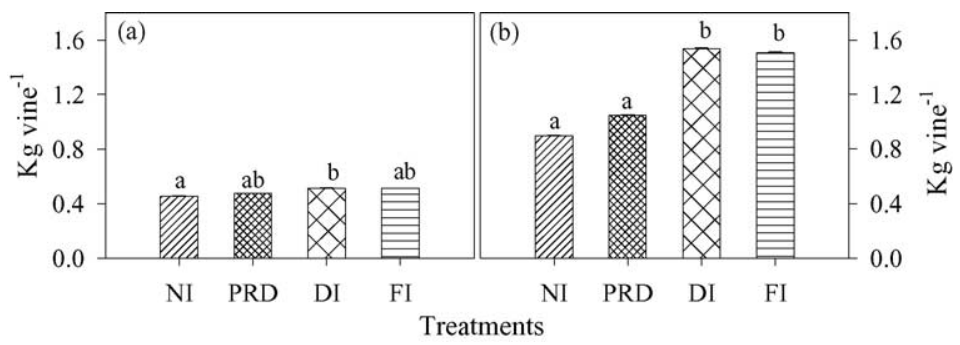

Fig. 8. Effects of different water treatments on pruning weight in Moscatel (a) and Castelão (b). Values are mean \pm S.E. Different letter suffixes show statistically significant differences $(P<0.05)$. 
growing season was probably due to the aging of leaves, since precocity of vegetation in this cultivar is higher as compared to Moscatel.

Water stress had no effects on the maximal primary photochemical efficiency of PSII, determined in darkadapted leaves in both cultivars. Permanent photoinhibition in grapevines was shown to be rare under drought (Flexas et al., 1999; Maroco et al., 2002; de Souza et al., 2003).

It is also interesting to note the large scattering of $A$ and $g_{\mathrm{s}}$ when related to $\psi_{\mathrm{pd}}$ (Fig. 4), especially in cultivar Moscatel, indicates a higher resilience of carbon assimilation and stomatal conductance to dehydration, so that high values can be maintained for a large range of leaf water potentials (from -0.2 down to -0.4 MPa). Furthermore, the cv. Moscatel has been considered well adapted to water stress conditions, showing high values of $g_{\mathrm{s}}$ when others cultivars had already reached values near to zero (Regina and Carbonneau, 1996). On the other hand, $\psi_{\text {pd }}$ may not be the best indicator of the intensity of water stress, because deep roots may be influencing $\psi_{\text {pd }}$, whereas stomata may be responding to signals resulting from dehydration of superficial roots, before any change in leaf water potential is detectable. Mid morning $g_{\mathrm{s}}$ has been suggested as an integrative parameter to reflect water stress experienced by plants, namely in grapevines (Flexas et al., 2002; Medrano et al., 2002). In our study, a good correlation between several physiological parameters and midday $g_{\mathrm{s}}$ was observed in both cultivars (Fig. 5) indicating that $g_{\mathrm{s}}$ rather than $\psi_{\mathrm{pd}}$ is a better indicator of water stress intensity.

Some studies have shown that the decreased photosynthesis under water deficit can be also associated with perturbations of the biochemical process (Correia et al., 1990; Tezara et al., 1999, 2002; Lawlor and Cornic, 2002; Parry et al., 2002). In the present study, the relative importance of stomatal versus metabolic limitations was assessed from $A / C_{\mathrm{i}}$ curves (Fig. 6) and key enzymes of the Calvin Cycle (Fig. 7). Although we are aware of the occurrence of patchy stomatal conductance, which can induce artefacts in $C_{\mathrm{i}}$ calculations (for review see Mott and Buckley, 1998), it has been acknowledged that under field conditions the effects of patchiness may be minimized (Guanasekera and Berkowitz, 1992), because the plants are subjected to a relatively gradual rate of stress imposition. Indeed, in a study with a different grapevine cultivar, cv. Tempranillo, Maroco et al. (2002) showed a good agreement between stomatal versus non-stomatal effects estimated both from biochemical measurements and $A / C_{\mathrm{i}}$ estimates.

We observed that $J_{\max }$ (related to RuBP regeneration) and TPU were more affected by water deficits than $V_{\text {cmax }}$ (dependent on Rubisco activity). In fact, we observed no statistically significant differences in $V_{\text {cmax }}$ among treatments in accordance with the reported higher resistance of Rubisco activity to water stress than photophosphorylation (Giménez et al., 1992; Tezara et al., 1999). Under mild stress, Escalona et al. (1999) did not observe a significant reduction in Rubisco carboxylation efficiency for $\psi_{\mathrm{pd}}$ of $-0.5 \pm 0.04 \mathrm{MPa}$, in the cultivar Tempranillo of grapevines. However, under severe drought $\left(\psi_{\mathrm{pd}}\right.$ around $-1.0 \mathrm{MPa}$ ) a significant decrease in $V_{\text {cmax }}$ was reported by Maroco et al. (2002) in field-grown grapevines.

The biochemical limitations of photosynthesis were also evaluated by measurements of in vitro activities of key enzymes of Calvin Cycle, namely G3PDH, RuP5PK and FruBPase (Fig. 7), which are involved in RuBP regeneration and triose-P utilization. In our study, even in NI vines that reached $\psi_{\mathrm{pd}}$ values of $-0.7 \mathrm{Mpa}$, no statistically significant reductions on the activities of those enzymes were observed. Because leaf $\mathrm{N}$ content also did not decrease under lower water availability, our results support previous studies indicating a high stability of the biochemical photosynthetic machinery under water deficit.

Although there were no significant reductions in RuP5PK, one of the enzymes involved in RuBP regeneration, there was a decrease of $J_{\max }$ in stressed vines. The reduced $J_{\max }$ could be related to inhibition of ATP synthesis as reported by some authors (Tezara et al., 1999; Lawlor, 2002). Furthermore, the reductions in the mesophyll conductance to $\mathrm{CO}_{2}\left(g_{\text {mes }}\right)$ between the intercellular spaces and the chloroplasts that will restrict the $\mathrm{CO}_{2}$ availability to the chloroplast, may also explain the reduced $J_{\max }$ observed (Centritto et al., 2003; Ethier and Livingston, 2004). The reductions in some parameters from $A-C_{\mathrm{i}}$ curve analyses (as $J_{\max }$ and TPU) observed in stressed plants might be underestimated by a reduction in $g_{\text {mes }}$, not considered in the parameterization. In grapevines, the apparent carboxylation efficiency and the compensation point for $\mathrm{CO}_{2}$ remained unchanged under severe 
drought when analysed on a chloroplastic $\mathrm{CO}_{2}$ concentration $\left(C_{\mathrm{c}}\right)$, rather than $C_{\mathrm{i}}$, basis, suggesting that previously reported metabolic impairment was probably due to decreased $g_{\text {mes }}$ (Flexas et al., 2002). Therefore, our results contribute to confirm that reduction in grapevines photosynthesis under mild to moderate drought is mainly due to an increase in the resistance of $\mathrm{CO}_{2}$ diffusion mainly by stomatal closure, but probably also by reduced mesophyll conductance.

\section{Conclusion}

In conclusion, our results showed that water status of PRD vines remained closer to FI than DI, especially at midday, suggesting that PRD may restrict stomatal conductance, as compared to equivalent water availability for the plants, as in the case of the DI treatment. Depressive effects of PRD on shoot growth were present in Castelão, the most drought sensitive cultivar. Differences among varieties may be related to differences in sensitivity of stomata, shoot growth and/or the interaction between rootstock and cultivar to soil water availability. We also observed a high resistance of the photosynthetic apparatus of grapevine leaves to restricted water availability under field conditions. In fact, the decreased stomatal conductance observed in some cases in PRD vines had no major negative impact on carbon assimilation. The benefits of PRD and DI relative to FI were the restricted water consumption with similar $\mathrm{CO}_{2}$ assimilation leading to improved water use efficiency. Although the differences between the PRD and DI treatments in our study were subtle, they may become more marked in years or regions with lower precipitation, as well as with more drought responsive varieties.

\section{Acknowledgements}

The financial support from EU project IRRISPLIT (IAC3-CT-1999-00008) is acknowledged. CRS was a recipient of a doctoral fellowship granted by Fundação para Ciência e Tecnologia (PRAXIS XXI/BD/21856/ 99). We also thank A. Rodrigues and E. Breia for technical support in the laboratory and field experiment.

\section{References}

Alegre, S., Girona, J., Marsal, J., Arbones, A., Mata, M., Montagut, D., Teixido, F., Motilva, M.J., Romero, M.P., 1999. Regulated deficit irrigation on olives trees. Acta Hort. 474, 373376.

Bjökman, O., Demmig, B., 1987. Photon yield of $\mathrm{O}_{2}$ evolution and chlorophyll fluorescence characteristics at $77 \mathrm{~K}$ among vascular plants of diverse origins. Planta 170, 489-504.

Boland, A.M., Mitchell, P.D., Jerie, P.H., Goodwin, I., 1993. The effect of regulated deficit irrigation on tree water use and growth of peach. J. Hort. Sci. 68, 261-274.

Centritto, M., Loreto, F., Chartzoulakis, K., 2003. The use of low $\left[\mathrm{CO}_{2}\right]$ to estimate diffusional and non-diffusional limitations of photosynthetic capacity of salt-stressed olive saplings. Plant Cell Environ. 26, 585-594.

Chaves, M.M., Pereira, J.S., Maroco, J., Rodrigues, M.L., Ricardo, C.P.P., Osório, M.L., Carvalho, I., Faria, T., Pinheiro, C., 2002. How plants cope with water stress in the field. Photosynthesis and growth. Ann. Bot. 89, 907-916.

Correia, M.J., Chaves, M.M., Pereira, J.S., 1990. Afternoon depression in photosynthesis in grapevine leaves: evidence for a high light stress effect. J. Exp. Bot. 41, 417-426.

Davies, W.J., Bacon, M.A., Thompson, D.S., Sobeih, W., Rodríguez, L.G., 2000. Regulation of leaf and fruit growth in plants growing in drying soil: exploitation of the plants' chemical signalling system and hydraulic architecture to increase the efficiency of water use in agriculture. J. Exp. Bot. 51, 1617-1626.

de Souza, C.R., Maroco, J.P., Santos, T., Rodrigues, M.L., Lopes, C., Pereira, J.S., Chaves, M.M., 2003. Partial rootzone-drying: regulation of stomatal aperture and carbon assimilation in field grown grapevines (Vitis vinifera cv. Moscatel). Funct. Plant Biol. 30, 653-662.

dos Santos, T., Lopes, C.M., Rodrigues, M.L., Souza, C.R., Maroco, J.P., Pereira, J.S., Silva, J.R., Chaves, M.M., 2003. Partial rootzone drying: effects on growth, and fruit quality of fieldgrown grapevines (Vitis vinifera L.). Funct. Plant Biol. 30, 663671.

Dry, P.R., Loveys, B.R., During, H., 2000a. Partial drying of the rootzone of grape. I. Transient changes in shoot growth and gas exchange. Vitis 39, 3-7.

Dry, P.R., Loveys, B.R., During, H., 2000b. Partial drying of the rootzone of grape. II. Changes in the pattern of root development. Vitis 39, 9-12.

Dry, P.R., Loveys, B.R., McCarthy, M.G., Stoll, M., 2001. Strategic management in Australian vineyards. J. Int. Sci. Vigne Vin 35, 129-139.

Escalona, J.M., Flexas, J., Medrano, H., 1999. Stomatal and nonstomatal limitations of photosynthesis under water stress in field-grown grapevines. Aust. J. Plant Physiol. 26, 421-433.

Ethier, G.J., Livingston, N.J., 2004. On the need to incorporate sensitivity to $\mathrm{CO}_{2}$ transfer conductance into the Farquhar-von Caemmerer-berry leaf photosynthesis model. Plant Cell Environ. 27, 137-153.

Farquhar, G.D., von Caemmerer, S., Berry, J.A., 1980. A biochemical model of photosynthesis $\mathrm{CO}_{2}$ assimilation in leaves of $\mathrm{C}_{3}$ plants species. Planta 149, 78-90. 
Flexas, J., Escalona, J.M., Medrano, H., 1999. Water stress induces different levels of photosynthesis and electron transport rate regulation in grapevines. Plant Cell Environ. 22, 3948.

Flexas, J., Bota, J., Escalona, J.M., Sampol, B., Medrano, H., 2002. Effects of drought on photosynthesis under field conditions: an evaluation of stomatal and mesophyll limitations. Funct. Plant Biol. 29, 461-471.

Fort, C., Fauveau, M.L., Muller, F., Label, P., Granier, A., Dreyer, E., 1997. Stomatal conductance, growth and root signaling in young oak seedlings subjected to partial soil drying. Tree Physiol. 17, 281-289.

Fort, C., Muller, F., Label, P., Granier, A., Dreyer, E., 1998. Stomatal conductance, growth and root signaling in Betula pendula seedlings subjected to partial soil drying. Tree Physiol. 18, 769-776.

Giménez, D., Mitchell, V.J., Lawlor, D., 1992. Regulation of photosynthesis rate of two sun flower hybrids under water stress. Plant Physiol. 98, 516-524.

Guanasekera, D., Berkowitz, G.A., 1992. Heterogeneous stomatal closure in response to leaf water deficits is not a universal phenomenon. Plant Physiol. 98, 660-665.

Harley, P.C., Thomas, R.B., Reynolds, J.F., Strain, B.R., 1992. Modelling photosynthesis of cotton grown in elevated $\mathrm{CO}_{2}$. Plant Cell Environ. 15, 271-282.

Holbrook, N.M., Sashidhar, V.R., James, R.A., Munns, R., 2002. Stomatal control in tomato with ABA deficient roots: response of grafted plants of soil drying. J. Exp. Bot. 53, 1503-1514.

Jackson, D.I., Lombard, P.B., 1993. Environmental and management practices affecting grape composition and wine quality-a review. Am. J. Enol. Vitic. 44, 409-430.

Lawlor, D.W., 2002. Limitation to photosynthesis in water-stressed leaves: stomata vs. metabolism and the role of ATP. Ann. Bot. 89, 871-885.

Lawlor, D.W., Cornic, G., 2002. Photosynthetic carbon assimilation and associated metabolism in relation to water deficits in higher plants. Plant Cell Environ. 25, 275-294.

Liu, L., McDonald, A.J.S., Stadenberg, I., Davies, W.J., 2001. Stomatal and leaf growth response to partial drying of root tips in willow. Tree Physiol. 21, 765-770.

Loveys, B.R., 1984. Diurnal changes in water relations and abscisic acid in field grown Vitis vinifera cultivars. III. The influence of xylem derived abscisic on leaf gas exchange. New Phytol. 98, 563-573.

Loveys, B.R., Dry, P.R., Stoll, M., McCarthy, M.G., 2000. Using plant physiology to improve the water efficiency of horticultural crops. Acta Hort. 537, 187-197.

Maroco, J.P., Rodrigues, M.L., Lopes, C., Chaves, M.M., 2002. Limitations to leaf photosynthesis in field-grown grapevine under drought-metabolic and modelling approaches. Funct. Plant Biol. 29, 1-9.

Matthews, M.A., Anderson, M.M., 1988. Fruit ripening in Vitis vinifera $\mathrm{L}$.: responses to seasonal water deficits. Am. J. Enol. Vitic. 39, 313-320.

Matthews, M.A., Anderson, M.M., 1989. Reproductive development in grape (Vitis vinifera $\mathrm{L}$.): responses to seasonal water deficits. Am. J. Enol. Vitic. 40, 52-60.

McCarthy, M.G., 1997. The effect of transient water deficit on berry development of cv. Shiraz (Vitis vinifera L.). Aust. J. Grape Wine Res. 3, 102-108.

Medrano, H., Escalona, J.M., Bota, J., Gulías, J., Flexas, J., 2002. Regulation of photosynthesis of $\mathrm{C}_{3}$ plants in response to progressive drought: stomatal conductance as a reference parameter. Ann. Bot. 89, 895-905.

Mott, K.A., Buckley, T.N., 1998. Stomatal heterogeneity. J. Exp. Bot. 49, 407-417.

Parry, M.A.J., Andralojc, P.J., Khan, S., Lea, P.J., Keys, A.J., 2002. Rubisco activity: effects of drought stress. Ann. Bot. 89, 833838.

Prichard, T.L., 1992. A volume balance approach to quality wine grape irrigation. In: Walker, M.A., Kliewer, W.M. (Eds.), Viticultural Practices. University of California, Davies, USA, pp. 12-23.

Regina, M.A., Carbonneau, A., 1996. Trocas gasosas em Vitis vinifera sob regime de estresse hídrico. I. Caracterização do comportamento varietal. Pesq. Agrop. Bras 31, 869-876.

Saab, I.N., Sharp, R.E., 1989. Non-hydraulic signals from maize roots in drying soil: inhibition of leaf elongation but not stomatal conductance. Planta 179, 466-474.

Sharkey, T.D., 1985. Photosynthesis in intact leaves of $\mathrm{C}_{3}$ plants: physics, physiology and rate limitations. Bot. Rev. 78, 71-75.

Stoll, M., Loveys, B., Dry, P., 2000. Hormonal changes induced by partial rootzone drying of irrigated grapevine. J. Exp. Bot. 51, 1627-1634.

Tezara, W., Mitchell, V.J., Driscoll, S.D., Lawlor, D.W., 1999. Water stress inhibits plant photosynthesis by decreasing coupling factor and ATP. Nature 401, 914-917.

Tezara, W., Mitchell, V., Driscoll, S.P., Lawlor, D.W., 2002. Effects of water deficit and its interaction with $\mathrm{CO}_{2}$ supply on the biochemistry and physiology of photosynthesis in sunflower. J. Exp. Bot. 53, 1781-1791.

Zhang, J., Davies, W.J., 1989a. Abscisic acid produced in dehydrating roots may enable the plant to measure the water status of the soil. Plant Cell Environ. 12, 73-81.

Zhang, J., Davies, W.J., 1989b. Sequential response of whole plant water reactions to prolonged soil drying and the involvement of xylem sap ABA in the regulation of stomatal behaviour of sunflower plants. New Phytol. 113, 167-174. 